\title{
Copolymers incorporated with $\beta$-substituted acrylate synthesized by organo-catalyzed group-transfer polymerization
}

\author{
Motosuke Imada ${ }^{1,2,3} \cdot$ Yasumasa Takenaka $\mathbb{(}^{1} \cdot$ Takeharu Tsuge $\mathbb{C}^{2} \cdot$ Hideki Abe ${ }^{1,2}$
}

Received: 25 January 2021 / Revised: 19 March 2021 / Accepted: 5 April 2021 / Published online: 19 May 2021

(c) The Author(s) 2021. This article is published with open access

\begin{abstract}
Various copolymers incorporated with $\beta$-substituted acrylates, such as alkyl crotonates (e.g., methyl crotonate (MC), ethyl crotonate (EC), isopropyl crotonate (iPC), and $n$-butyl crotonate (nBC)) and methyl cinnamate (MCin), were synthesized by group-transfer polymerization (GTP) using a silicon-based Lewis acid catalyst. In addition to $\beta$-substituted acrylates, $\alpha$ substituted acrylates (e.g., methyl methacrylate (MMA) and $n$-butyl methacrylate (nBMA)) were examined as comonomers. Proton nuclear magnetic resonance $\left({ }^{1} \mathrm{H}\right.$ NMR) spectroscopy and matrix-assisted laser desorption/ionization time-of-flight mass spectrometry (MALDI-TOF-MS) characterizations of the obtained copolymers revealed that each monomer component was incorporated sufficiently. The thermal stabilities of the resulting copolymers were investigated by dynamic mechanical analysis (DMA), indicating that the glass-transition temperature $\left(T_{\mathrm{g}}\right)$ of the copolymers can be widely varied over a relatively high-temperature range by selecting the optimal comonomer. More specifically, the $T_{\mathrm{g}}$ values of poly(MC-random-EC) $(\mathrm{MC} / \mathrm{EC}$ molar ratio $=50 / 50)$, poly $(\mathrm{MC}-$ random $-\mathrm{nBC}) \quad(\mathrm{MC} / \mathrm{nBC}$ molar ratio $=50 / 50)$, poly $(\mathrm{MC}-$ random $-\mathrm{MC}$ in $)$ $(\mathrm{MC} / \mathrm{MC}$ in molar ratio $=54 / 46)$, and poly $(\mathrm{nBC}-$ random-MCin $)(\mathrm{nBC} / \mathrm{MCin}$ molar ratio $=56 / 44)$ were $173,130,216$, and $167^{\circ} \mathrm{C}$, respectively.
\end{abstract}

\section{Introduction}

Group-transfer polymerization (GTP) was developed as a controlled living-polymerization method of (meth)acrylates by Webster et al. in the 1980s [1]. The first-generation GTP system used fluoride ions and silyl ketene acetals (SKAs) as the catalyst and the initiator, respectively. Since then, numerous improvements have been made to the GTP system to control the living-polymerization fashion and expand the range of available monomer substrates. Hertler et al.

Supplementary information The online version contains supplementary material available at https://doi.org/10.1038/s41428021-00493-z.

Yasumasa Takenaka

yasumasa.takenaka@riken.jp

1 Bioplastic Research Team, RIKEN Center for Sustainable Resource Science, Saitama, Japan

2 Department of Materials Science and Engineering, Tokyo Institute of Technology, Yokohama, Japan

3 Research Center, Innovation and Business Development Division, Nippon Shokubai Co., Ltd, Osaka, Japan reported that Lewis acids, such as zinc halides, organo aluminum, and $\mathrm{HgI}_{2}$, can be applied to the controlled GTP of acrylates [2-6]. In addition, Kakuchi et al. developed a highly efficient organo-catalyzed GTP system using a silicon-based Lewis acid catalyst [7, 8].

Crotonic acid, cinnamic acid, and their derivatives are $\beta$ substituted acrylic compounds possessing a methyl or phenyl group at the $\beta$-position of the $\alpha, \beta$-unsaturated carbonyl compound $[9,10]$. The addition polymerization of these compounds is challenging because of the steric hindrance and/or electrical factor of the $\beta$-substituent [11-21]. In this context, Chen et al. recently developed a frustrated Lewis pair-catalyzed polymerization system for methyl crotonate (MC) and indenone, which used an $\mathrm{N}$-heterocyclic carbene or hydrosilane as a Lewis base and an aluminum or boron compound as a Lewis acid [22-24]. In addition, Ute et al. developed a GTP system for the homopolymerization of various alkyl crotonates using an inorganic Lewis acid $\left(\mathrm{HgI}_{2}\right.$ or $\left.\mathrm{CdI}_{2}\right)$ as the catalyst and iodotrialkylsilane as the cocatalyst [25-28]. Furthermore, our group reported that the organo-catalyzed GTP system using $N$-(trimethylsilyl)bis (trifluoromethanesulfonyl)imide $\left(\mathrm{Tf}_{2} \mathrm{NSiMe}_{3}\right)$ and 1-trimethylsiloxyl-1-methoxy-2-methyl-1-propene (MTS), as described by Kakuchi et al., is applicable to the efficient 
Scheme 1 Copolymerization strategies toward $\beta$-substituted acrylates via GTP using

$\mathrm{Tf}_{2} \mathrm{NSi}^{t} \mathrm{BuMe}_{2}$ and ${ }^{t \mathrm{BuMe} 2} \mathrm{SKA}$

\section{One-stage copolymerization}

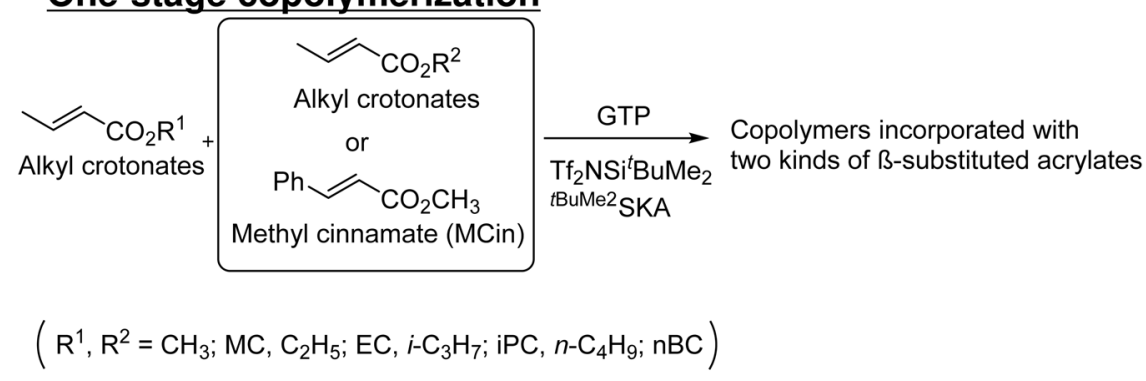

Two-stage copolymerization

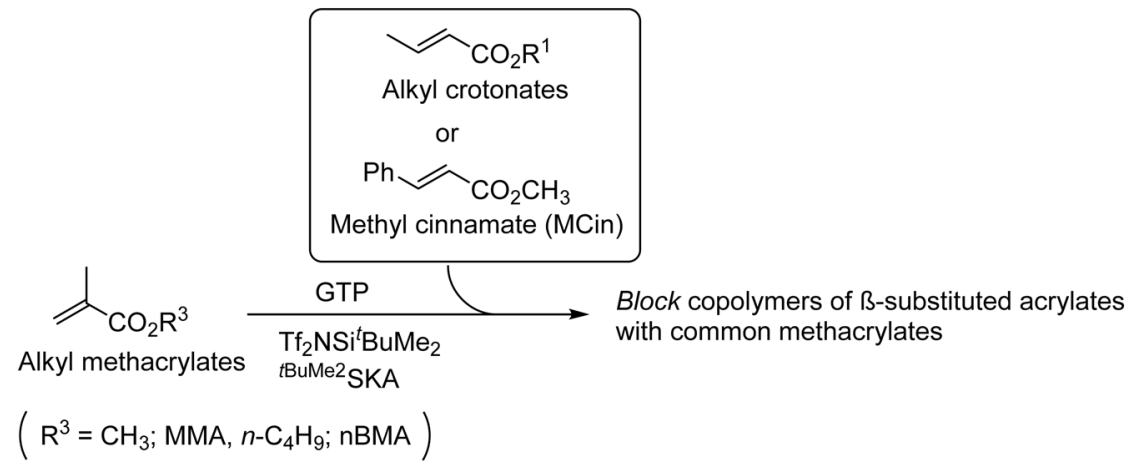

homopolymerization of various alkyl crotonates and cinnamates $[29,30]$. These studies also demonstrated that the homopolymers synthesized from $\beta$-substituted acrylates exhibit relatively high thermal stabilities, likely due to the contribution of the stiff polymer main chain bearing substituents at the $\alpha$ - and $\beta$ positions.

Because copolymerization can greatly enhance the extent of currently attainable polymeric properties, investigations into the copolymerizability and the applicable comonomer range of $\beta$-substituted acrylates could expand the potential polymer applications [31-34]. However, our GTP system did not guarantee copolymerization because the living chain end was frequently deactivated via cyclization termination reactions $[29,30,35,36]$. Recently, we demonstrated that changing the silyl groups of $\mathrm{Tf}_{2} \mathrm{NSiMe}_{3}$ and MTS to a bulkier group, such as a tert-butyldimethylsilyl moiety, is an effective means for suppressing termination reactions in the GTP system [37]. Thus, we herein report our investigation into the copolymerization of $\beta$-substituted acrylates (i.e., crotonates and cinnamate) using an organo-catalyzed GTP system with $\mathrm{N}$-(tert-butyldimethylsilyl)bis(trifluoromethanesulfonyl)imide $\left(\mathrm{Tf}_{2} \mathrm{NSi}^{t} \mathrm{BuMe}_{2}\right)$ and 1-methoxy-1-(tert-butyldimethylsiloxy)2-methyl-1-propene $\left({ }^{t \mathrm{BuMe} 2} \mathrm{SKA}\right)$. Two types of copolymerization strategies are evaluated based on different monomer feed methods. More specifically, a one-stage copolymerization is conducted to obtain a random copolymer, where two types of monomers are added simultaneously to the polymerization system. In addition, two-stage polymerization is conducted to obtain a block copolymer, where one monomer is homopolymerized in the first stage, and a second feed of comonomer is subsequently added to the system. The series of copolymers prepared via this one-stage copolymerization approach incorporate two types of $\beta$-substituted acrylates selected from MC: ethyl crotonate (EC), isopropyl crotonate (iPC), $n$-butyl crotonate $(\mathrm{nBC})$, and methyl cinnamate (MCin). Moreover, block copolymers of $\beta$-substituted acrylates with common methacrylates, such as methyl methacrylate (MMA) and $n$-butyl methacrylate (nBMA), are prepared by the two-stage copolymerization approach using the livingpolymerization characteristics of the GTP system (Scheme 1). To the best of our knowledge, examples of addition copolymerization strategies incorporating cinnamates into the polymer backbone are limited [38-40]. We also investigated the thermal stabilities of a series of obtained copolymers by dynamic mechanical analysis (DMA) and thermogravimetric analysis (TGA).

\section{Experimental}

\section{Materials}

MC, EC, iPC, nBC, MCin, MMA, nBMA, methyl isobutyrate, tert-butyldimethylchlorosilane, $N, N$ '-dimethylpropyleneurea, lithium(diisopropylamide) (1.5 M in THF), and bis(trifluoromethanesulfonyl)imide $\left(\mathrm{Tf}_{2} \mathrm{NH}\right)$ were obtained from Tokyo Chemical Industry Co., Ltd. $\mathrm{CH}_{2} \mathrm{Cl}_{2}$ and tetrahydrofuran (THF) (Kanto Chemical Co., 
superdehydrated grade) were purified using an SPS 800 system (MBraun). Argon and nitrogen were purified before use by passing through a dry clean column $(4 \AA$ molecular sieves) and a gas clean CC-XR column purchased from Nikka Seiko. All monomers, except MCin, were distilled using $\mathrm{CaH}_{2}$ and stored in a glovebox. MCin was purified using 3 and $4 \AA$ molecular sieves in $\mathrm{CH}_{2} \mathrm{Cl}_{2}$ and stored in a glovebox.

\section{Synthesis of 1-methoxy-1-(tert-butyldimethylsiloxy)- 2-methyl-1-propene) ( $\left.{ }^{\mathrm{BuMe}} \mathrm{SKA}\right)$}

1-Methoxy-1-(tert-butyldimethylsiloxy)-2-methyl-1-propene $\left({ }^{t \mathrm{BuMe} 2} \mathrm{SKA}\right)$ was synthesized by the reaction of methyl isobutyrate and tert-butyldimethylchlorosilane, in accord with the literature [41]. More specifically, a solution of methyl isobutyrate $(14.0 \mathrm{~g}, 137 \mathrm{mmol})$ in THF $(200 \mathrm{~mL})$ was charged to a flask filled with dry nitrogen gas, after which a $1.5 \mathrm{M}$ lithium(diisopropylamide) THF solution $(100 \mathrm{~mL}, 150 \mathrm{mmol})$ was added dropwise with vigorous stirring at $-78{ }^{\circ} \mathrm{C}$ over $30 \mathrm{~min}$. Subsequently, a solution of $N, N^{\prime}$-dimethylpropyleneurea $(200 \mathrm{mmol})$ and tert-butyldimethylchlorosilane $(22.6 \mathrm{~g}, 150 \mathrm{mmol})$ in THF $(50 \mathrm{~mL})$ was added, and stirring continued at $-78^{\circ} \mathrm{C}$ for $60 \mathrm{~min}$. Next, the reaction mixture was warmed to room temperature and stirred for $24 \mathrm{~h}$ before concentration. The resulting mixture was taken up in hexane $(500 \mathrm{~mL})$, washed with water $(3 \times 100 \mathrm{~mL})$, saturated aqueous $\mathrm{NaHCO}_{3}(100 \mathrm{~mL})$, and brine $(100 \mathrm{~mL})$, and then dried over anhydrous $\mathrm{MgSO}_{4}$. After filtration, the organic layer was concentrated. Distillation under vacuum conditions gave the desired ${ }^{t \mathrm{BuMe} 2} \mathrm{SKA}$ as a clear, colorless liquid (54\% yield) with a purity of $>99 \%$, as determined by proton nuclear magnetic resonance $\left({ }^{1} \mathrm{H}\right.$ NMR) spectroscopy.

\section{Measurements}

All molecular weight data for the polymer samples were obtained by gel permeation chromatography (GPC) at $40{ }^{\circ} \mathrm{C}$ using a Shimadzu GPC system equipped with an RID-10A refractive index detector, a Shodex GPC K-802 column, and a Shodex GPC K-806 M column. $\mathrm{CHCl}_{3}$ was used as the eluent at a flow rate of $0.8 \mathrm{~mL} \mathrm{~min}^{-1}$. Polystyrene standards with a low polydispersity were used to obtain a calibration curve.

${ }^{1} \mathrm{H}$ NMR and ${ }^{13} \mathrm{C}$ NMR measurements were performed on a Varian NMR system. The samples were dissolved in $\mathrm{CDCl}_{3}$, and $500 \mathrm{MHz}{ }^{1} \mathrm{H}$ NMR spectra were recorded at room temperature. The $125 \mathrm{MHz}{ }^{13} \mathrm{C}$ NMR spectra were recorded at room temperature in a $\mathrm{CDCl}_{3}$ solution. The data were calibrated against tetramethylsilane (TMS, $\delta 0.00$ ) and analyzed using Mnova NMR software.
Matrix-assisted laser desorption/ionization time-of-flight mass spectrometry (MALDI-TOF-MS) was conducted on an ultrafleXtreme MALDI-TOF spectrometer (Bruker Daltonics, Billerica, MA) operating in linear mode at an accelerating voltage of $20 \mathrm{kV}$. Samples for MALDI-TOFMS comprised combinations of the polymer $(2 \mu \mathrm{L})$, the matrix (1,8-dihydroxy-9(10H)-anthracenone (dithranol), $10 \mathrm{mg} \mathrm{mL}^{-1}, 8 \mu \mathrm{L}$ ), and the ionizing agent (sodium trifluoroacetate, $10 \mathrm{mg} \mathrm{mL}^{-1}, 2 \mu \mathrm{L}$ ) in THF. Samples were deposited on an MTP 384 ground steel target plate. External calibration was conducted before data acquisition. The detected mass list was extracted using FlexAnalysis software (Bruker Daltonics).

TGA was performed on an SII Nano Technology TG/DTA7200 thermal analyzer from room temperature to $500{ }^{\circ} \mathrm{C}$ in a nitrogen atmosphere at a heating rate of $10^{\circ} \mathrm{C}$ $\min ^{-1} \cdot T_{\mathrm{d} 5}$ and $T_{\mathrm{d} 50}$ were defined as the temperature at which the weight loss reached $5 \%$ and $50 \%$, respectively, of the total weight.

The $T_{\mathrm{g}}$ of each polymer sample was measured by DMA (Perkin Elmer DMA800) under a nitrogen atmosphere by cooling the sample to $-50{ }^{\circ} \mathrm{C}$ at a rate of $10{ }^{\circ} \mathrm{C} \mathrm{min}{ }^{-1}$ and then recording the DMA scan from -50 to $+250^{\circ} \mathrm{C}$ at a heating rate of $5^{\circ} \mathrm{C} \mathrm{min}^{-1}$ and a frequency of $1 \mathrm{~Hz}$.

\section{Group-transfer polymerization}

All manipulations were performed in a dry and oxygen-free argon atmosphere using standard high-vacuum Schlenk techniques or a glovebox. A typical procedure for the onestage polymerization process (entry 3 , Table 1 ) was as follows: MC (501 mg, $5 \mathrm{mmol}), \mathrm{nBC}(711 \mathrm{mg}, 5 \mathrm{mmol})$, ${ }^{t \mathrm{BuMe} 2}$ SKA $(10.8 \mathrm{mg}, 0.050 \mathrm{mmol})$, and $\mathrm{CH}_{2} \mathrm{Cl}_{2}(6.0 \mathrm{~mL})$ were charged to a Schlenk tube in a glovebox. A $\mathrm{CH}_{2} \mathrm{Cl}_{2}$ solution $(2.7 \mathrm{~mL})$ of $\mathrm{Tf}_{2} \mathrm{NH}(7.0 \mathrm{mg}, 0.025 \mathrm{mmol})$ was added to initiate the polymerization reaction at $0{ }^{\circ} \mathrm{C}$. After $48 \mathrm{~h}$, methanol $(10 \mathrm{~mL})$ was added to the reaction mixture, after which the solvents were removed by evaporation under reduced pressure. The residue was then dissolved in $\mathrm{CHCl}_{3}$, and the solution was poured into a large volume of hexane. The precipitated polymer was collected as the hexane-insoluble component by filtration, washed several times with hexane, and dried under vacuum for $24 \mathrm{~h}$. For the two-stage polymerization process (entry 8, Table 1), the procedure was as follows: $\mathrm{MC}(501 \mathrm{mg}, 5 \mathrm{mmol})$, ${ }^{t B u M e 2}$ SKA $(10.8 \mathrm{mg}, 0.050 \mathrm{mmol})$, and $\mathrm{CH}_{2} \mathrm{Cl}_{2}(4.0 \mathrm{~mL})$ were charged to a Schlenk tube in a glovebox. $\mathrm{A} \mathrm{CH}_{2} \mathrm{Cl}_{2}$ solution $(2.7 \mathrm{~mL})$ of $\mathrm{Tf}_{2} \mathrm{NH}(7.0 \mathrm{mg}, 0.025 \mathrm{mmol})$ was added to initiate the polymerization reaction at $0{ }^{\circ} \mathrm{C}$. After $24 \mathrm{~h}, \mathrm{C} \mathrm{CH}_{2} \mathrm{Cl}_{2}$ solution $(2.0 \mathrm{~mL})$ of $\mathrm{nBC}(711 \mathrm{mg}, 5 \mathrm{mmol})$ was added dropwise, and the polymerization reaction was allowed to continue for an additional $24 \mathrm{~h}$. The second 
Table 1 Summarized data for the copolymerization of two types of $\beta$-substituted acrylates ${ }^{\mathrm{a}}$

\begin{tabular}{|c|c|c|c|c|c|c|c|c|c|c|c|c|c|c|}
\hline Entry & $M^{1}$ & $M^{2}$ & $\begin{array}{l}\text { Initiator } \\
\text { mmol }\end{array}$ & $\begin{array}{l}\text { Catalyst } \\
\text { mmol }\end{array}$ & $\begin{array}{l}\text { Solvent } \\
\mathrm{mL}\end{array}$ & $\begin{array}{l}{\left[M^{1}\right]_{0}} \\
\mathrm{~mol} \mathrm{~L}^{-1}\end{array}$ & $\begin{array}{l}{\left[M^{2}\right]_{0}} \\
\mathrm{~mol} \mathrm{~L}^{-1}\end{array}$ & $\begin{array}{l}\text { Time } \\
\mathrm{h}\end{array}$ & $\begin{array}{l}x^{1 \mathrm{c}} \\
\%\end{array}$ & $\begin{array}{l}x^{2 \mathrm{c}} \\
\%\end{array}$ & $\begin{array}{l}\text { yield }^{\mathrm{d}} \\
\%\end{array}$ & $\begin{array}{l}M_{\mathrm{n}}{ }^{\mathrm{e}} \\
\mathrm{g} \mathrm{mol}^{-1}\end{array}$ & $\begin{array}{l}Ð^{\mathrm{e}} \\
M_{\mathrm{w}} / M_{\mathrm{n}}\end{array}$ & $\begin{array}{l}f^{\mathrm{f}} \\
\%\end{array}$ \\
\hline 1 & $\mathrm{MC}$ & $\mathrm{EC}$ & 0.025 & 0.025 & 8.9 & 0.50 & 0.50 & 48 & 100 & 100 & 100 & 84,500 & 1.18 & 51 \\
\hline 2 & $\mathrm{MC}$ & iPC & 0.025 & 0.025 & 8.8 & 0.50 & 0.50 & 96 & 61 & 87 & 59 & 76,600 & 1.14 & 45 \\
\hline 3 & MC & $\mathrm{nBC}$ & 0.025 & 0.025 & 8.7 & 0.50 & 0.50 & 48 & 100 & 100 & 100 & 107,600 & 1.18 & 45 \\
\hline 4 & MC & MCin & 0.10 & 0.10 & 6.5 & 0.64 & 0.64 & 168 & 100 & 84 & 95 & 24,900 & 1.26 & 48 \\
\hline 5 & EC & MCin & 0.10 & 0.10 & 6.4 & 0.64 & 0.64 & 168 & 100 & 85 & 94 & 25,200 & 1.25 & 50 \\
\hline 6 & iPC & MCin & 0.10 & 0.10 & 6.3 & 0.64 & 0.64 & 168 & 100 & 41 & 62 & 16,300 & 1.23 & 60 \\
\hline 7 & $\mathrm{nBC}$ & MCin & 0.10 & 0.10 & 6.3 & 0.64 & 0.64 & 168 & 100 & 79 & 83 & 27,800 & 1.19 & 49 \\
\hline $8^{\mathrm{b}}$ & $\mathrm{MC}$ & $\mathrm{nBC}$ & 0.025 & 0.025 & 8.7 & 0.69 & - & $24+24$ & 100 & 20 & 44 & 53,100 & 1.10 & 48 \\
\hline $9^{\mathrm{b}}$ & $\mathrm{nBC}$ & $\mathrm{MC}$ & 0.025 & 0.025 & 8.7 & 0.69 & - & $24+24$ & 100 & 10 & 59 & 63,900 & 1.09 & 48 \\
\hline
\end{tabular}

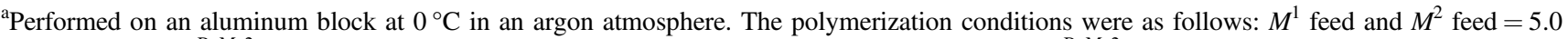
mmol, initiator $={ }^{t \mathrm{BuMe} 2} \mathrm{SKA}$, catalyst $=\mathrm{Tf}_{2} \mathrm{NSi}^{t} \mathrm{BuMe}_{2}$ (generated via the in situ reaction between ${ }^{t \mathrm{BuMe} 2} \mathrm{SKA}$ and $\mathrm{Tf}_{2} \mathrm{NH}(\mathrm{Scheme} \mathrm{S} 1, \mathrm{Supporting}$ Information)), solvent $=\mathrm{CH}_{2} \mathrm{Cl}_{2} \cdot M^{1}$ and $M^{2}$ were fed simultaneously into the polymerization system (one-stage polymerization)

${ }^{\mathrm{b}}$ Two-stage polymerization was conducted. $M^{1}$ was homopolymerized for $24 \mathrm{~h}$ in the first stage, and then a second feed of $M^{2}$ was added to the system. The second stage of polymerization was conducted for an additional $24 \mathrm{~h}$

${ }^{\mathrm{c}}$ Monomer conversions $\left(x^{1}=M^{1}\right.$ conv., and $x^{2}=M^{2}$ conv.) were calculated directly using ${ }^{1} \mathrm{H}_{\mathrm{NMR}}$ measurements $\left(500 \mathrm{MHz}, \mathrm{rt}, \mathrm{CDCl}_{3}\right)$ of the reaction mixture

${ }^{\mathrm{d}}$ The polymer yield was calculated based on the total weight of the feed monomers

${ }^{\mathrm{e}}$ The number-averaged molecular weight $\left(M_{\mathrm{n}}\right)$ and dispersity $(\nexists)$ were determined using conventional GPC against PSt standards in $\mathrm{CHCl}_{3}$ ${ }^{\mathrm{f}}$ Initiator efficiency: $f=$ [molecular weight of polymer calculated by a feed ratio]/[number-average molecular weight of polymers determined by GPC]

monomer feed was introduced without sampling from the first step because this manipulation may deactivate the living polymers by introducing trace amounts of water. Finally, the reaction was worked up using the same process that was employed for the one-stage polymerization.

\section{Results and discussion}

\section{Copolymerization using two types of $\beta$-substituted acrylates}

Initially, the preparation of a series of copolymers incorporating two types of $\beta$-substituted acrylates $\left(M^{1}\right.$ and $\left.M^{2}\right)$ selected from the $\mathrm{MC}, \mathrm{EC}, \mathrm{PC}, \mathrm{nBC}$, and MCin groups was attempted by GTP using $\mathrm{Tf}_{2} \mathrm{NSi}^{t} \mathrm{BuMe}_{2}$ (generated via the in situ reaction between ${ }^{t \mathrm{BuMe} 2} \mathrm{SKA}$ and $\mathrm{Tf}_{2} \mathrm{NH}$ (Scheme $\mathrm{S} 1$, Supporting Information)) as the catalyst and ${ }^{t \mathrm{BuMe} 2} \mathrm{SKA}$ as the initiator in $\mathrm{CH}_{2} \mathrm{Cl}_{2}$ at $0{ }^{\circ} \mathrm{C}$ at a molar feed ratio of $M^{1}$ : $M^{2}=1: 1$. Table 1 summarizes the conversions of $M^{1}$ and $M^{2}$ ( $x^{1}$ and $x^{2}$, respectively), the polymer yields, the number-average molecular weights $\left(M_{\mathrm{n}}\right)$, and the dispersities $(\nexists)$ of the obtained polymers. Figure 1 shows the GPC curves for the synthesized polymers.

When the polymerization reaction was conducted using a simultaneous feed of $M^{1}$ and $M^{2}$ (one-stage polymerization) (entries 1-7, Table 1), the consumption of both monomers was observed. In the cases of entries $1-3$, the use of MC as $M^{1}$ and an alkyl crotonate (EC, iPC, or nBC) as $M^{2}$, where the molar feed ratio of the sum of $M^{1}$ and $M^{2}$ versus the

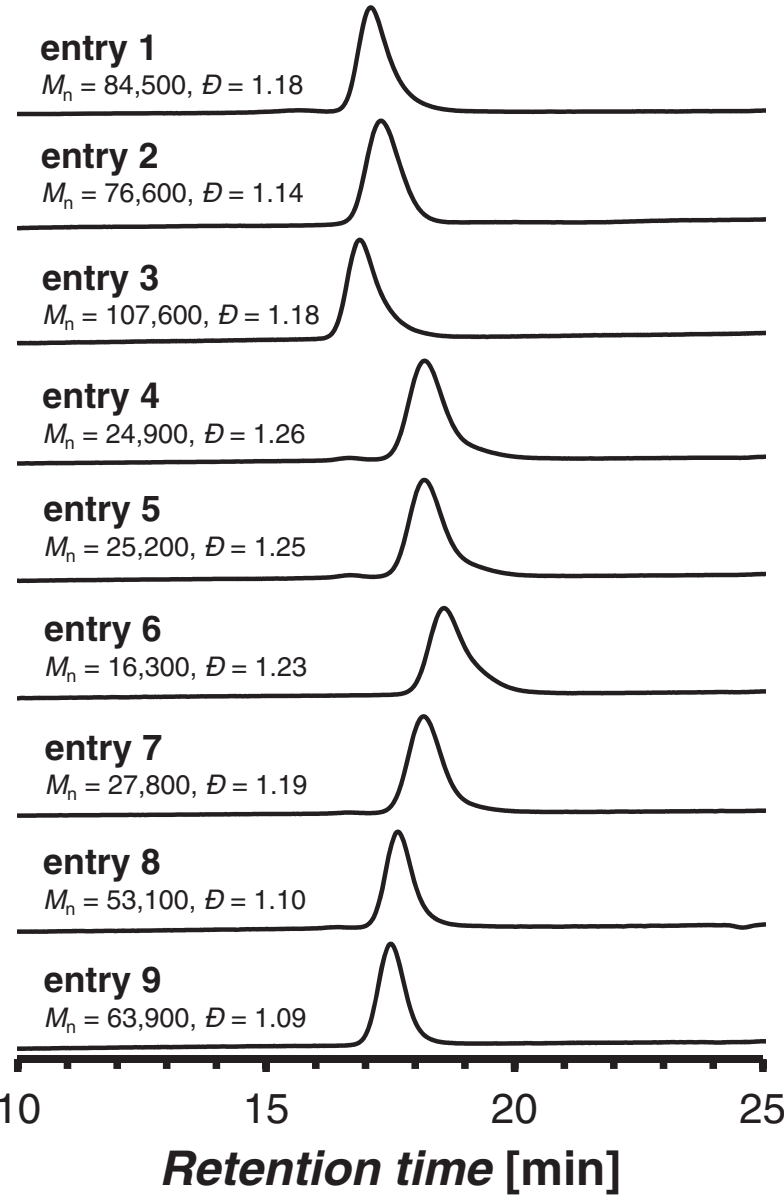

Fig. 1 GPC curves of the obtained polymers for the reaction presented in entries 1-9 (Table 1) 
(a)

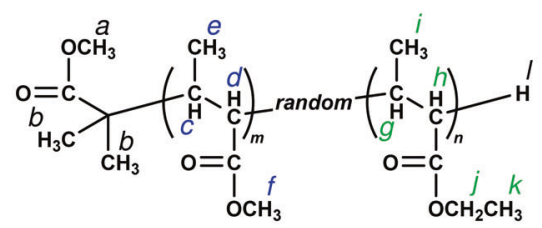

Comopolymer of MC with EC
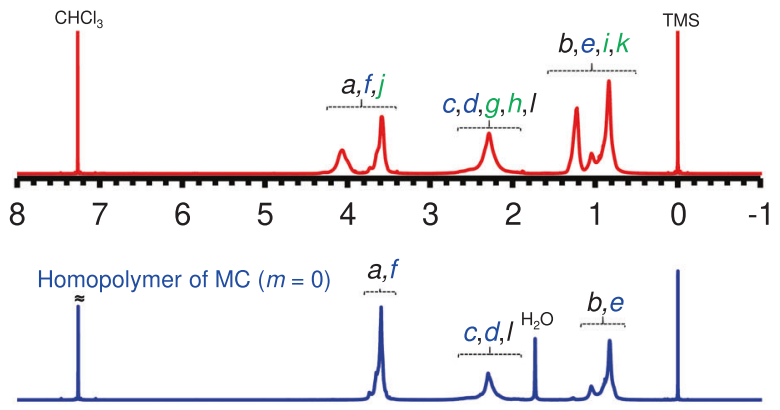

Homopolymer of EC $(n=0)$

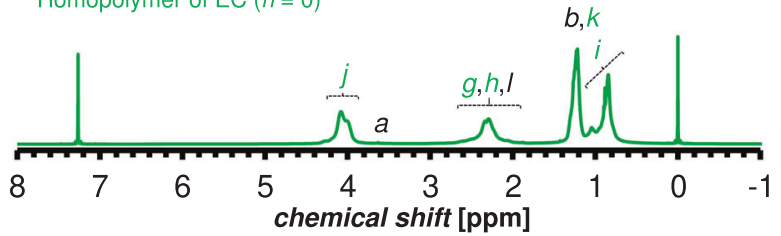

Fig. $2{ }^{1} \mathrm{H}$ NMR spectra (red lines) of the polymers synthesized from a MC as $M^{1}$ and EC as $M^{2}$ (entry 1, Table 1) and $\mathbf{b}$ EC as $M^{1}$ and MCin as $M^{2}$ (entry 5 , Table 1 ), measured at $500 \mathrm{MHz}$ in $\mathrm{CDCl}_{3}$ at room

initiator was 400 , polymers possessing a high molecular weight $\left(M_{\mathrm{n}}>76 \mathrm{~kg} \mathrm{~mol}^{-1}\right)$ and a relatively narrow dispersity $(\nexists<1.2)$ were obtained. In particular, the polymer obtained by the reaction outlined in entry 3 (i.e., from $\mathrm{MC}$ and $\mathrm{nBC}$ ) exhibited a high molecular weight of $>107 \mathrm{~kg} \mathrm{~mol}^{-1}$. In terms of entries 4-7, the use of alkyl crotonates (MC, EC, iPC, or $\mathrm{nBC}$ ) as $M^{1}$ and MCin as $M^{2}$, where the molar feed ratio of the sum of $M^{1}$ and $M^{2}$ versus the initiator was 100 , gave polymers possessing a relatively high molecular weight $\left(M_{\mathrm{n}}>24 \mathrm{~kg} \mathrm{~mol}^{-1}\right)$ and a relatively narrow dispersity $(\Theta<$ 1.3). The exception to this rule was entry 6 , where the reactivity of iPC was low, which was likely due to the steric hindrance of the ester group.

In the case of the two-stage polymerization process (entries 8 and 9, Table 1), where $M^{1}$ was homopolymerized for $24 \mathrm{~h}$ in the first stage, followed by a second feed of $M^{2}$ and polymerization for an additional $24 \mathrm{~h}$, the consumption of $M^{2}$ was barely observed. The molecular weights of the obtained polymers $\left(M_{\mathrm{n}}=53100 \mathrm{~g} \mathrm{~mol}^{-1}\right.$ in entry 8 and 63 $900 \mathrm{~g} \mathrm{~mol}^{-1}$ in entry 9) were clearly smaller than that obtained for the reaction of entry $3\left(M_{\mathrm{n}}=107600 \mathrm{~g} \mathrm{~mol}^{-1}\right)$, where the polymerization process was conducted under conditions identical to those for entries 8 and 9 , with the exception of the monomer feeding method. This result (b)

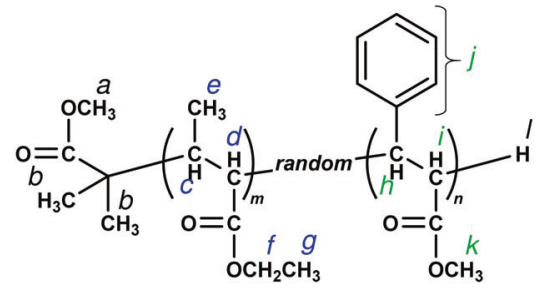

Comopolymer of EC with MCin

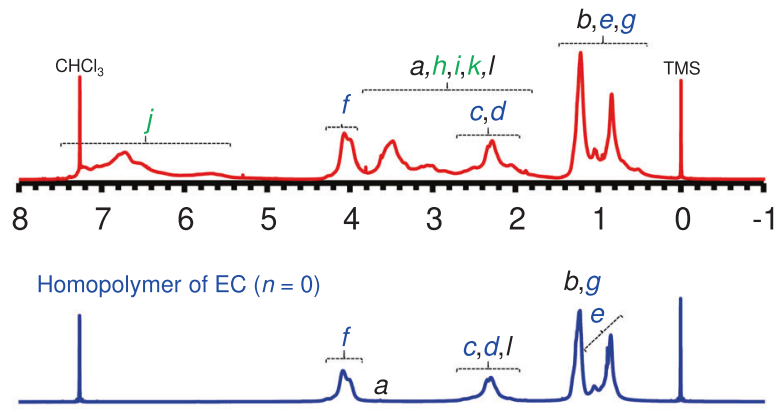

Homopolymer of MCin $(m=0)$

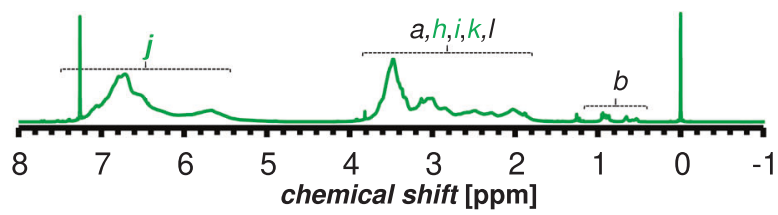

temperature. The blue and green lines represent the ${ }^{1} \mathrm{H}$ NMR spectra of the homopolymers synthesized from $M^{1}$ and $M^{2}$, respectively

suggests that in the two-stage polymerization of $\beta$-substituted acrylates, the amount of living polymer derived from $M^{1}$ was low during the additional $M^{2}$ feed. This deactivation of a living polymer is thought to be caused by a side reaction, such as an intramolecular termination reaction (e.g., terminal cyclization of the propagating chain-end groups), as proposed for the GTP system [35, 36].

\section{Structural analyses of the obtained polymers}

To confirm the structures of the obtained polymers, ${ }^{1} \mathrm{H}$ NMR analyses were conducted. Figure $2 \mathrm{a}$ shows the ${ }^{1} \mathrm{H}$ NMR spectrum of the polymer synthesized using MC as $M^{1}$ and EC as $M^{2}$ (entry 1, Table 1), in addition to those of poly (MC) and poly(EC), which were synthesized via a similar GTP route for comparison (Table S3, Supporting Information). Furthermore, Fig. $2 b$ shows the ${ }^{1} \mathrm{H}$ NMR spectrum of the polymer synthesized using EC as $M^{1}$ and MCin as $M^{2}$ (entry 5, Table 1), in addition to those of the prepared poly (EC) and poly(MCin) (Table S3, Supporting Information). As shown in Fig. 2a, the ${ }^{1} \mathrm{H}$ NMR spectrum of entry 1 agrees well with the overlap of the spectra of poly(MC) and poly(EC). Similarly, as shown in Fig. $2 b$, the ${ }^{1} \mathrm{H}$ NMR spectrum of entry 5 is comparable to the superposition of 

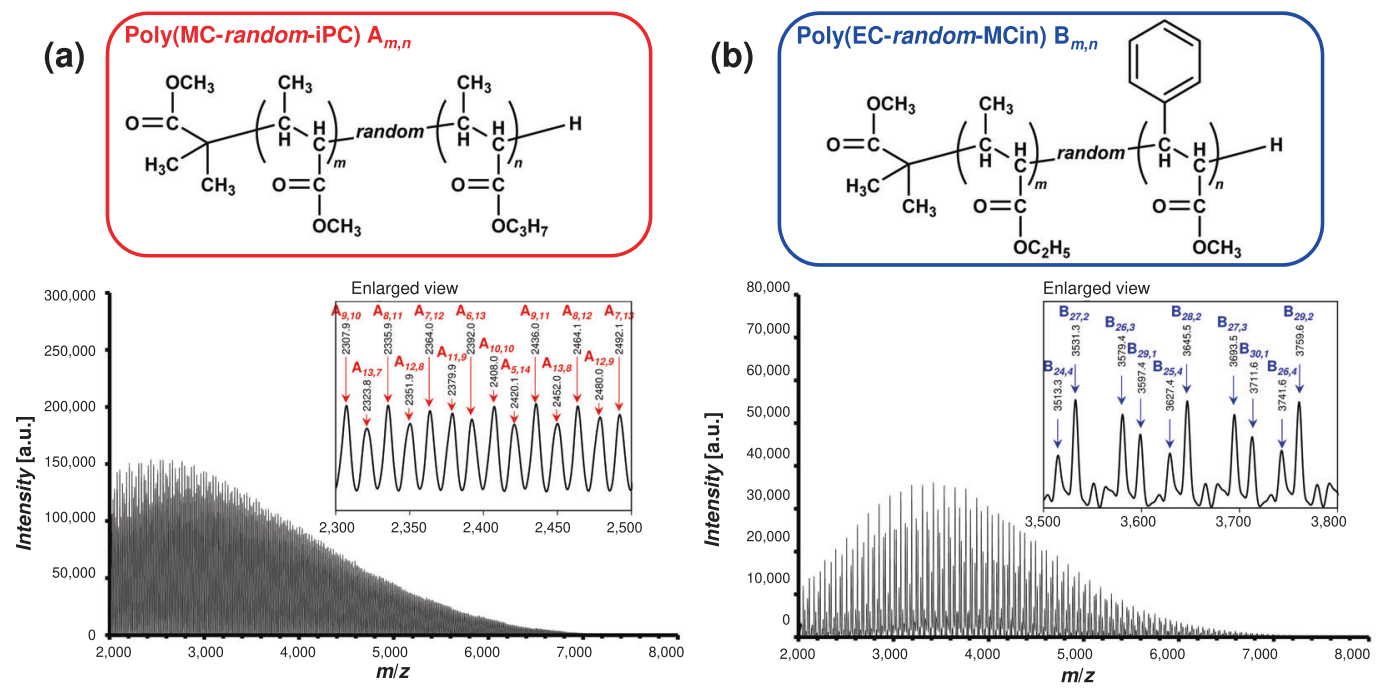

Fig. 3 MALDI-TOF-MS spectra of the polymers synthesized from a MC as $M^{1}$ and iPC as $M^{2}$ (entry 2, Table 1) and $\mathbf{b}$ EC as $M^{1}$ and MCin as $M^{2}$ (entry 5, Table 1), measured using dithranol as a matrix and $\mathrm{CF}_{3} \mathrm{COONa}$ as an ionizing agent

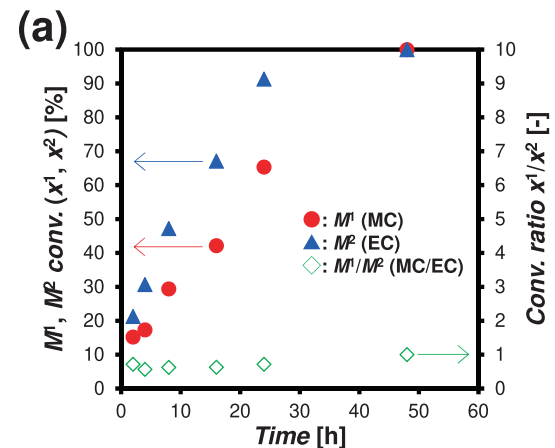

Fig. 4 Time-conversion curves for the copolymerization of a $\mathrm{MC}$ with EC and $\mathbf{b}$ EC with MCin. Copolymerization was conducted using ${ }^{t \mathrm{BuMe} 2} \mathrm{SKA}$ as the initiator and $\mathrm{Tf}_{2} \mathrm{NSi}^{t} \mathrm{BuMe}_{2}$ (generated via the in situ reaction between ${ }^{t \mathrm{BuMe} 2} \mathrm{SKA}$ and $\mathrm{Tf}_{2} \mathrm{NH}$ (Scheme S1, Supporting

the spectra of poly(EC) and poly(MCin). These results suggest that the consumed monomers $\left(M^{1}\right.$ and $\left.M^{2}\right)$ were successfully introduced into the polymer backbone.

The molecular structures of the obtained polymers were investigated in greater detail by MALDI-TOF-MS analysis. Figure $3 \mathrm{a}$ shows the mass spectrum of the polymer synthesized using MC as $M^{1}$ and iPC as $M^{2}$ (entry 2, Table 1), while Fig. $3 \mathrm{~b}$ shows the mass spectrum of the polymer synthesized using EC as $M^{1}$ and MCin as $M^{2}$ (entry 5 in Table 1).

From the detailed analysis, it was confirmed that the observed peaks correspond to the sum of the masses of the copolymers containing $M^{1}$ and $M^{2}$ generated by GTP using ${ }^{t \mathrm{BuMe} 2} \mathrm{SKA}$ and $\mathrm{Na}^{+}$(derived from $\mathrm{CF}_{3} \mathrm{COONa}$ added as an ionizing agent in the MALDI-TOF-MS measurements). The polymer shown in Fig. 3a was therefore determined to have the structural formula $\left(\mathrm{CH}_{3}\right)_{2}\left[\mathrm{CH}_{3} \mathrm{OC}(=\mathrm{O})\right] \mathrm{C}-(\mathrm{MC})_{m}$ $(\mathrm{iPC})_{n}-\mathrm{H}$, where the $\left(\mathrm{CH}_{3}\right)_{2}\left[\mathrm{CH}_{3} \mathrm{OC}(=\mathrm{O})\right] \mathrm{C}$ moiety at the initiation chain-end was derived from ${ }^{t \mathrm{BuMe} 2} \mathrm{SKA}$, and the

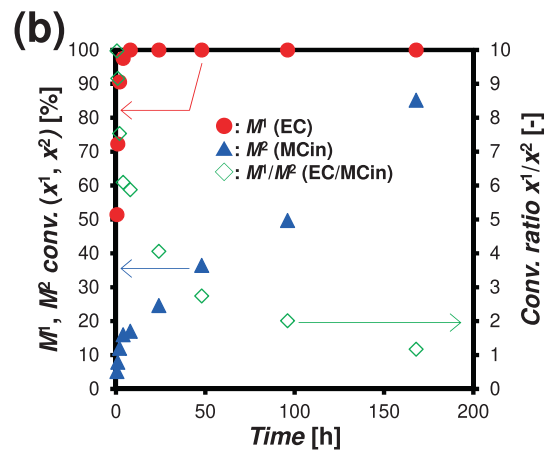

Information)) as the catalyst in $\mathrm{CH}_{2} \mathrm{Cl}_{2}$ at $0{ }^{\circ} \mathrm{C}$. The polymerization conditions were as follows: $\mathbf{a}[\mathrm{MC}]_{0}=[\mathrm{EC}]_{0}=0.50 \mathrm{M},\left[{ }^{\mathrm{BuMe} 2} \mathrm{SKA}\right]_{0}=$ $0.0025 \mathrm{M}$, and $\left[\mathrm{Tf}_{2} \mathrm{NSi}^{t} \mathrm{BuMe}_{2}\right]_{0}=0.0025 \mathrm{M}, \mathbf{b}[\mathrm{EC}]_{0}=[\mathrm{MCin}]_{0}=$ $\left.0.64 \mathrm{M},{ }^{\mathrm{tBuMe} 2} \mathrm{SKA}\right]_{0}=0.013 \mathrm{M}$, and $\left[\mathrm{Tf}_{2} \mathrm{NSi}^{t} \mathrm{BuMe}_{2}\right]_{0}=0.013 \mathrm{M}$

methylene group at the termination chain-end was generated by acid treatment of the terminal silyl ether group in the living polymer (Scheme S2, Supporting Information). Similarly, the polymer shown in Fig. $3 \mathrm{~b}$ was determined to have the structural formula $\left(\mathrm{CH}_{3}\right)_{2}\left[\mathrm{CH}_{3} \mathrm{OC}(=\mathrm{O})\right] \mathrm{C}-(\mathrm{EC})_{m}$ $(\mathrm{MCin})_{n}-\mathrm{H}$. Therefore, MALDI-TOF-MS structural analyses of the obtained polymers afforded clear evidence that copolymerization using a simultaneous feed of two types of $\beta$-substituted acrylates proceeded smoothly.

\section{Time-conversion curve}

Subsequently, we attained the time-conversion curve data to obtain information regarding the monomer unit arrangement in the copolymer backbone. Figure 4a shows the time-conversion curve for the copolymerization reaction using $\mathrm{MC}$ as $M^{1}$ and $\mathrm{EC}$ as $M^{2}$ (entry 1, Table 1), while Fig. $4 \mathrm{~b}$ shows the time-conversion curve for the 
Table 2 Summarized data for the copolymerization reactions of $\alpha$-substituted acrylates with $\beta$-substituted acrylates ${ }^{\mathrm{a}}$

\begin{tabular}{|c|c|c|c|c|c|c|c|c|c|c|c|c|c|c|}
\hline Entry & $M^{1}$ & $M^{2}$ & $\begin{array}{l}\text { Initiator } \\
\text { mmol }\end{array}$ & $\begin{array}{l}\text { Catalyst } \\
\text { mmol }\end{array}$ & $\begin{array}{l}\text { Solvent } \\
\mathrm{mL}\end{array}$ & $\begin{array}{l}{\left[M^{1}\right]_{0}} \\
\mathrm{~mol} \mathrm{~L}^{-1}\end{array}$ & $\begin{array}{l}{\left[M^{2}\right]_{0}} \\
\mathrm{~mol} \mathrm{~L}^{-1}\end{array}$ & $\begin{array}{l}\text { Time } \\
\mathrm{h}\end{array}$ & $\begin{array}{l}x^{1 \mathrm{~d}} \\
\%\end{array}$ & $\begin{array}{l}x^{2 d} \\
\%\end{array}$ & $\begin{array}{l}\text { Yield }^{\mathrm{e}} \\
\%\end{array}$ & $\begin{array}{l}M_{\mathrm{n}}{ }^{\mathrm{f}} \\
\mathrm{g} \mathrm{mol}^{-1}\end{array}$ & $\begin{array}{l}\bigoplus^{\mathrm{f}} \\
M_{\mathrm{w}} / M_{\mathrm{n}}\end{array}$ & $\begin{array}{l}f^{\mathrm{g}} \\
\% \\
\end{array}$ \\
\hline 10 & MMA & $\mathrm{MC}$ & 0.025 & 0.025 & 8.9 & 1.0 & - & $24+24$ & 78 & 81 & 72 & $58,300^{\mathrm{h}}$ & $1.27^{\mathrm{h}}$ & 55 \\
\hline 11 & MMA & $\mathrm{nBC}$ & 0.025 & 0.025 & 8.7 & 1.0 & - & $24+24$ & 79 & 97 & 81 & $77,000^{\mathrm{h}}$ & $1.25^{\mathrm{h}}$ & 56 \\
\hline 12 & nBMA & $\mathrm{MC}$ & 0.025 & 0.025 & 8.7 & 1.0 & - & $24+24$ & 73 & 70 & 56 & $57,600^{\mathrm{h}}$ & $1.24^{\mathrm{h}}$ & 60 \\
\hline 13 & nBMA & $\mathrm{nBC}$ & 0.025 & 0.025 & 8.4 & 1.0 & - & $24+24$ & 78 & 100 & 84 & $68,200^{\mathrm{h}}$ & $1.23^{\mathrm{h}}$ & 75 \\
\hline 14 & nBMA & $\mathrm{MC}$ & 0.025 & 0.025 & 8.7 & 1.0 & - & $12+24$ & 51 & 92 & 59 & 56,300 & 1.21 & 59 \\
\hline 15 & nBMA & MCin & 0.100 & 0.100 & 6.3 & 1.0 & - & $6+162$ & 100 & 38 & 67 & 16,800 & 1.17 & 61 \\
\hline $16^{\mathrm{b}}$ & $\mathrm{MC}$ & nBMA & 0.025 & 0.025 & 8.7 & 1.0 & - & $24+24$ & 100 & 4 & 40 & 49,300 & 1.11 & 43 \\
\hline $17^{\mathrm{c}}$ & nBMA & $\mathrm{MC}$ & 0.025 & 0.025 & 8.7 & 0.50 & 0.50 & 48 & 6 & 90 & 35 & 46,700 & 1.16 & 42 \\
\hline
\end{tabular}

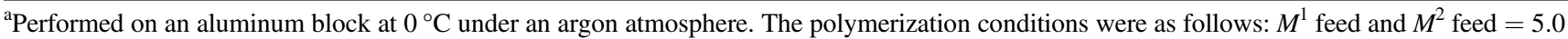
mmol, initiator $={ }^{t \mathrm{BuMe} 2} \mathrm{SKA}$, catalyst $=\mathrm{Tf}_{2} \mathrm{NSi}^{t} \mathrm{BuMe}_{2}$ (generated via the in situ reaction between ${ }^{t \mathrm{BuMe} 2} \mathrm{SKA}$ and $\mathrm{Tf}_{2} \mathrm{NH}$ ( $\mathrm{Scheme} \mathrm{S} 1$, Supporting Information)), solvent $=\mathrm{CH}_{2} \mathrm{Cl}_{2}$. Two-stage polymerization was conducted. $M^{1}$ was homopolymerized in the first stage, and then a second feed of $M^{2}$ was added to the polymerization system

${ }^{\mathrm{b}} \mathrm{MC}$ was used as $M^{1}$, and nBMA was used as $M^{2}$

${ }^{\mathrm{c}} M^{1}$ and $M^{2}$ were fed simultaneously into the polymerization system

${ }^{\mathrm{d}}$ Monomer conversions ( $x^{1}=M^{1}$ conv., $x^{2}=M^{2}$ conv.) were calculated directly using ${ }^{1} \mathrm{H}$ NMR measurements $\left(500 \mathrm{MHz}, \mathrm{rt}, \mathrm{CDCl}_{3}\right)$ of the reaction mixture

${ }^{\mathrm{e}}$ The polymer yield was calculated based on the total weight of the feed monomers $\left(M^{1}\right.$ and $\left.M^{2}\right)$

${ }^{\mathrm{f}}$ The number-averaged molecular weight $\left(M_{\mathrm{n}}\right)$ and dispersity $(\nexists)$ were determined using conventional GPC against PSt standards in $\mathrm{CHCl}_{3}$

${ }^{\mathrm{g}}$ Initiator efficiency: $f=$ [molecular weight of polymer calculated by a feed ratio]/[number-average molecular weight of polymers determined by GPC]

${ }^{\mathrm{h}}$ Bimodal in GPC as for entries $10-13$

copolymerization reaction using EC as $M^{1}$ and MCin as $M^{2}$ (entry 5, Table 1).

As shown in Fig. 4a, the conversion ratio of $M^{1}(\mathrm{MC})$ versus $M^{2}$ (EC) was within the range of $0.5-1$ from the initial term to the end term of the copolymerization process, suggesting that the polymerization rate of EC was only slightly faster than that of MC. This result indicates that in the case of the copolymer obtained for the reaction outlined in entry 1 (Table 1), the $\mathrm{MC}$ and $\mathrm{EC}$ monomer units were incorporated throughout the polymer backbone.

In contrast, as shown in Fig. 4(b), the conversion of $M^{1}$ (EC) was approximately tenfold greater than that of $M^{2}$ (MCin) in the initial stage of copolymerization. This result indicates that in the case of entry 5 (Table 1), EC monomer units were primarily incorporated at the head part of the polymer backbone, while MCin monomer units were mainly incorporated at the tail end. Thus, copolymerization using two types of $\beta$-substituted acrylates with greatly different polymerizabilities leads to the generation of a $\mathrm{gra}$ dient-like random copolymer.

\section{Copolymer of $a$-substituted acrylate and $\beta$-substituted acrylate}

Subsequently, the preparation of a series of copolymers from an $\alpha$-substituted acrylate ( $M^{1}$, MMA or nBMA) and a $\beta$-substituted acrylate $\left(M^{2}, \mathrm{MC}, \mathrm{nBC}\right.$, or $\left.\mathrm{MCin}\right)$ was attempted using the GTP protocol with $\mathrm{Tf}_{2} \mathrm{NSi}^{t} \mathrm{BuMe}_{2}$ as the catalyst and ${ }^{t \mathrm{BuMe} 2} \mathrm{SKA}$ as the initiator in $\mathrm{CH}_{2} \mathrm{Cl}_{2}$ at $0{ }^{\circ}$ $\mathrm{C}$, using a molar feed ratio of $M^{1}: M^{2}=1: 1$. Table 2 summarizes the conversions of $M^{1}$ and $M^{2}$ ( $x^{1}$ and $x^{2}$, respectively), the polymer yields, and the $M_{\mathrm{n}}$ and $Ð$ values of the obtained polymers, while Fig. 5 shows their GPC curves.

In the case of the two-stage polymerization reactions, where the $\alpha$-substituted acrylate was homopolymerized in the first stage, followed by a second feed of the $\beta$ substituted acrylate and an additional polymerization phase (entries 10-15, Table 2), sufficient consumption of both monomers was observed. When MMA or nBMA was employed as $M^{1}$ and an alkyl crotonate (MC or $\mathrm{nBC}$ ) was used as $M^{2}$, where the molar feed ratio of the sum of $M^{1}$ and $M^{2}$ versus the initiator was 400 (entries 10-14, Table 2), polymers possessing a relatively high molecular weight $\left(M_{\mathrm{n}}\right.$ $>56 \mathrm{~kg} \mathrm{~mol}^{-1}$ ) were obtained. In contrast, (entry 15 , Table 2), when nBMA was used as $M^{1}$ and MCin was employed as $M^{2}$, where the molar feed ratio of the sum of $M^{1}$ and $M^{2}$ versus the initiator was 100 , a polymer possessing a relatively low molecular weight of $16,800 \mathrm{~g} \mathrm{~mol}^{-1}$ was obtained.

On the other hand, in the case of entry 16 (Table 2), where the first feed monomer was a $\beta$-substituted acrylate (MC) and the second feed monomer was an $\alpha$-substituted acrylate (nBMA), the conversion of nBMA was particularly low $\left(x^{2}<10 \%\right)$. In addition, in the case of entry 17 , where 


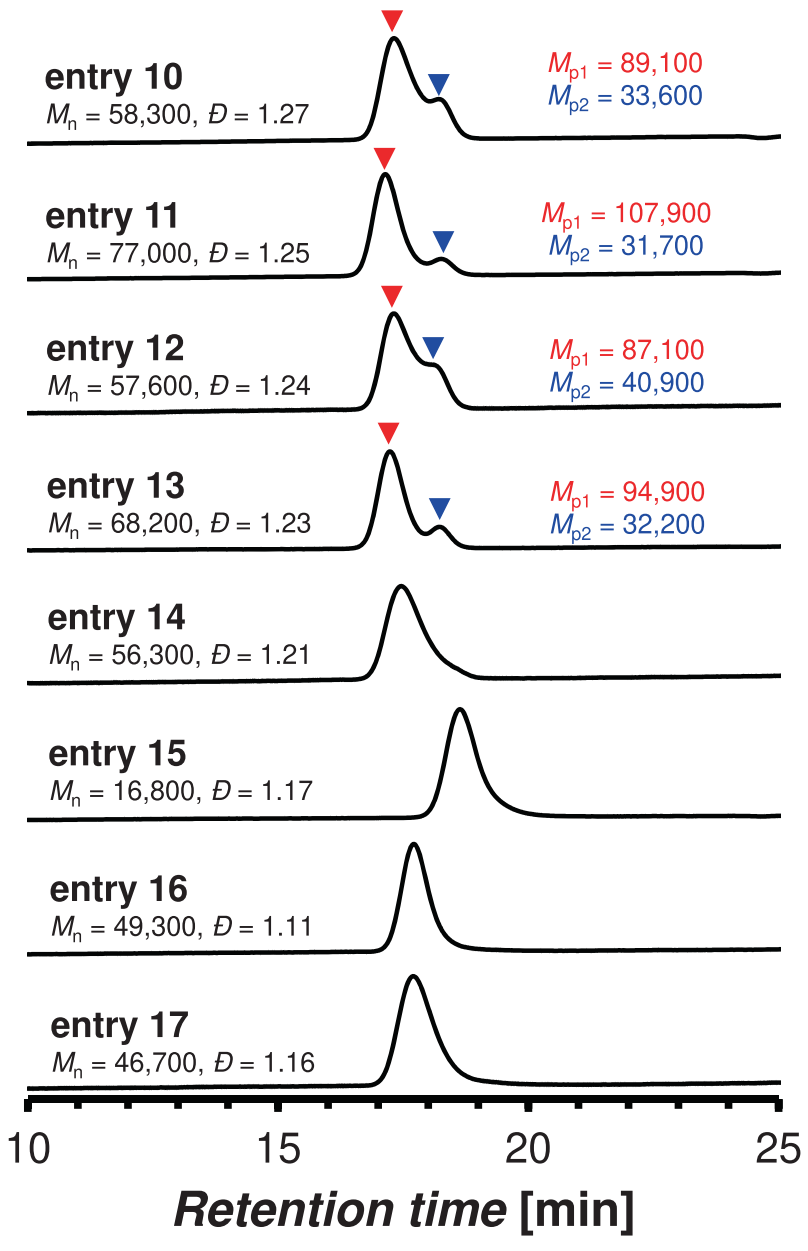

Fig. 5 GPC curves of the polymers obtained from the reactions outlined in entries 10-17 (Table 2). The blue and red inverted triangles represent lower- and higher-molecular-weight polymers, respectively

one-stage copolymerization was conducted, the conversion of the $\alpha$-substituted acrylate (nBMA) was low $(<10 \%)$. The molecular weights of the obtained polymers $\left(M_{\mathrm{n}}=49300 \mathrm{~g}\right.$ $\mathrm{mol}^{-1}$ for entry $16, M_{\mathrm{n}}=46700 \mathrm{~g} \mathrm{~mol}^{-1}$ for entry 17$)$ were smaller than that of entry $12\left(M_{\mathrm{n}}=57600 \mathrm{~g} \mathrm{~mol}^{-1}\right)$, despite the polymerization process being conducted under conditions identical to those used for entries 16 and 17 (with the exception of the monomer feeding method). These results suggest that the living chain end derived from the $\beta$-substituted acrylate exhibits poor reactivity toward the $\alpha$ substituted acrylate monomer. In addition, it was suggested that the living chain end derived from a $\beta$-substituted acrylate is more susceptible to a termination reaction, such as a cyclization reaction, than that derived from an $\alpha$-substituted acrylate [29, 35, 36] (Table S1 and Fig. S35, Supporting Information).

As shown in Fig. 5, the polymers obtained from the reactions outlined in entries 10-13 (Table 2) exhibit bimodal peaks in their GPC curves that correspond to lower- and higher molecular weight polymers. The peaks corresponding to a lower molecular weight were attributed to the homopolymers of the $\alpha$-substituted acrylate generated by a termination reaction (e.g., cyclization reaction) of the living chain end in the first stage. On the other hand, the peaks corresponding to a higher-molecular weight were attributed to the block copolymers of $M^{1}$ and $M^{2}$, which propagated from the living homopolymers of the $\alpha$-substituted acrylate that were alive during the second feed of the $\beta$-substituted acrylate monomer (Table S2, Supporting Information).

The polymer corresponding to entry 14 was obtained by shortening the time of the first-stage polymerization of nBMA with respect to entry 12 ( $12 \mathrm{~h}$ for entry 14 c.f. $24 \mathrm{~h}$ for entry 12). As shown in Fig. 5, the polymer obtained by the reaction presented in entry 14 gave an almost unimodal peak by GPC. This result confirms the hypothesis that the observed bimodal peaks for entry 12 were caused by the terminated homopolymers of nBMA. In addition, this result indicates that the block copolymer content can be enhanced by optimizing the polymerization time in the first stage.

\section{Thermal properties of the copolymers}

We then investigated the thermal properties (i.e., $T_{\mathrm{g}}, T_{\mathrm{d} 5}$, and $T_{\mathrm{d} 50}$ ) of the obtained copolymers by DMA and TGA, as summarized in Table 3. In this study, $T_{\mathrm{g}}$ was defined as the temperature corresponding to the maximum $\tan \delta$ value in the DMA measurements because differential scanning calorimetry did not afford a clear $T_{\mathrm{g}}$.

Table 3 shows that the $T_{\mathrm{g}}$ values of the copolymers obtained in the reactions outlined in entries 1-7 and prepared from two types of $\beta$-substituted acrylates were $>130^{\circ} \mathrm{C}$, indicating a relatively high heat stability. This high $T_{\mathrm{g}}$ can be rationalized via the stiffness of the polymer main chain containing substituents at the $\alpha$-position (ester group) and the $\beta$-position (methyl or phenyl group). A high $T_{\mathrm{g}}$ was also confirmed for the homopolymers of $\beta$-substituted acrylates synthesized by GTP using $\mathrm{Tf}_{2} \mathrm{NSi}^{t} \mathrm{BuMe}_{2}$ and ${ }^{t \mathrm{BuMe} 2} \mathrm{SKA}$ (Table S3, Supporting Information). Comparing entry 4 (copolymer of MC with MCin) with entries 1-3 (copolymer of $\mathrm{MC}$ as $M^{1}$ with $\mathrm{EC}$, iPC, or $\mathrm{nBC}$, respectively, as $M^{2}$ ) shows that the copolymer obtained using the conditions outlined in entry 4 exhibited the highest $T_{\mathrm{g}}$. This result suggests that cinnamate is a better comonomer than crotonate for enhancing the $T_{\mathrm{g}}$ of the resulting copolymers. Among entries $1-3$, greater numbers of carbon atoms on the ester group of $M^{2}$ resulted in lower $T_{\mathrm{g}}$ values for the resulting copolymers. Similarly, among entries 4-7 (copolymers synthesized using $\mathrm{MC}, \mathrm{EC}, \mathrm{iPC}$, or $\mathrm{nBC}$, respectively, as $M^{1}$, and MCin as $M^{2}$ ), the ester group of crotonate (as $M^{1}$ ) significantly influenced the $T_{\mathrm{g}}$ value of the resulting copolymers. These results indicate that the $T_{\mathrm{g}}$ of the copolymers described herein can be varied over a relatively high-temperature range by selecting the optimal comonomer. 
Table 3 Thermal properties of the obtained copolymers

\begin{tabular}{llllllll}
\hline Entry & $M^{1}, M^{2}$ & $\begin{array}{l}\text { Molar ratio in copolymer }{ }^{\mathrm{a}} \\
M^{1} / M^{2}\end{array}$ & $\begin{array}{l}M_{\mathrm{n}}{ }^{\mathrm{b}} \\
\mathrm{g} \mathrm{mol}^{-1}\end{array}$ & $\begin{array}{l}Ð^{\mathrm{b}} \\
M_{\mathrm{w}} / M_{\mathrm{n}}\end{array}$ & $\begin{array}{l}T_{\mathrm{g}}{ }^{\mathrm{c}} \\
{ }^{\circ} \mathrm{C}\end{array}$ & $\begin{array}{l}T_{\mathrm{d} 5}{ }^{\mathrm{d}} \\
{ }^{\circ} \mathrm{C}\end{array}$ & $\begin{array}{l}T_{\mathrm{d} 50}{ }^{\mathrm{d}} \\
{ }^{\circ} \mathrm{C}\end{array}$ \\
\hline 1 & MC, EC & $50 / 50$ & 84,500 & 1.18 & 173 & 357 & 397 \\
2 & MC, iPC & $41 / 59$ & 76,600 & 1.14 & 153 & 326 & 376 \\
3 & MC, nBC & $50 / 50$ & 107,600 & 1.18 & 130 & 341 & 394 \\
4 & MC, MCin & $54 / 46$ & 24,900 & 1.26 & 216 & 343 & 378 \\
5 & EC, MCin & $54 / 46$ & 25,200 & 1.25 & 189 & 348 & 382 \\
6 & iPC, MCin & $71 / 29$ & 16,300 & 1.23 & 172 & 310 & 383 \\
7 & nBC, MCin & $56 / 44$ & 27,800 & 1.19 & 167 & 331 & 377 \\
10 & MMA, MC & $49 / 51$ & $58,300^{\mathrm{e}}$ & $1.27^{\mathrm{e}}$ & 132 & 348 & 393 \\
11 & MMA, nBC & $45 / 55$ & $77,000^{\mathrm{e}}$ & $1.25^{\mathrm{e}}$ & 116 & 333 & 383 \\
12 & nBMA, MC & $51 / 49$ & $57,600^{\mathrm{e}}$ & $1.24^{\mathrm{e}}$ & 51 & 325 & 389 \\
13 & nBMA, nBC & $44 / 56$ & $68,200^{\mathrm{e}}$ & $1.23^{\mathrm{e}}$ & 53 & 327 & 377 \\
15 & nBMA, MCin & $73 / 27$ & 16,800 & 1.17 & 58 & 285 & 318 \\
\hline
\end{tabular}

${ }^{\mathrm{a}}$ Calculated from the monomer conversions

${ }^{\mathrm{b}}$ The number-averaged molecular weight $\left(M_{\mathrm{n}}\right)$ and dispersity $(\nexists)$ were determined using conventional GPC against PSt standards in $\mathrm{CHCl}_{3}$

${ }^{\mathrm{c}} T_{\mathrm{g}}$ was defined as the temperature corresponding to the maximum $\tan \delta$ value in the DMA measurement

${ }^{\mathrm{d}} T_{\mathrm{d} 5}$ and $T_{\mathrm{d} 50}$ were defined as the temperatures at which the weight loss reached 5 and $50 \%$, respectively, of the total weight in a nitrogen atmosphere

${ }^{\mathrm{e}} \mathrm{Bimodal}$ in GPC as for entries 10-13
In terms of the block copolymers prepared from an $\alpha$-substituted acrylate (MMA or nBMA) and a $\beta$-substituted acrylate (MC, $\mathrm{nBC}$, or $\mathrm{MCin}$ ), the $T_{\mathrm{g}}$ corresponding to the poly(MMA) block was detected at approximately $116-32^{\circ}$ $\mathrm{C}$ (entries 10 and 11), while the $T_{\mathrm{g}}$ corresponding to the poly(nBMA) block was detected at approximately $51-58^{\circ} \mathrm{C}$ (entries 12,13 , and 15). It has been previously reported that the $T_{\mathrm{g}}$ of poly(MMA) ranges from $51-122^{\circ} \mathrm{C}$, while that of poly(nBMA) ranges from $15-50{ }^{\circ} \mathrm{C}$ [42]. In contrast, the value of $T_{\mathrm{g}}$ derived from the poly( $\beta$-substituted acrylate) block was confirmed only as an indistinguishable or a small region. Thus, the $T_{\mathrm{g}}$ values of the block copolymers in this DMA study strongly reflected the characteristics of the poly $(\alpha$-substituted acrylate).

Finally, in the context of their thermal decomposition, the copolymers obtained herein were found to exhibit relatively high heat resistance, with $T_{\mathrm{d} 5}>325^{\circ} \mathrm{C}$ and $T_{\mathrm{d} 50}>$ $376^{\circ} \mathrm{C}$. The exceptions to this rule were the copolymers obtained under the conditions presented in entries 6 (Table 1) and 15 (Table 2), which had relatively low molecular weights of $<20 \mathrm{~kg} \mathrm{~mol}^{-1}$.

\section{Conclusion}

We herein reported the preparation of various copolymers incorporated with $\beta$-substituted acrylates, such as alkyl crotonates (MC, EC, iPC, and $\mathrm{nBC}$ ), and MCin, via the
GTP process using a silicon-based Lewis acid catalyst and SKAs possessing a relatively bulky silyl moiety, such as the tert-butyldimethylsilyl group. Our results indicated that using this organo-catalyzed GTP system, the copolymerization of $\beta$-substituted acrylates could be achieved by selecting a suitable comonomer. When multiple $\beta$ substituted acrylates were used, a simultaneous monomer feed system was necessary to ensure smooth copolymerization. In addition, when an $\alpha$-substituted acrylate was used as the comonomer, a multistage copolymerization method (where the $\alpha$-substituted acrylate is homopolymerized in the first stage followed by a second feed of the $\beta$-substituted acrylate) resulted in the formation of a block copolymer incorporated with each component. This monomer feed method must consider the susceptibility of termination reactions and/or the copolymerizability of the living chain end derived from the monomers used. ${ }^{1} \mathrm{H}$ NMR spectroscopy and MALDI-TOF-MS were used to confirm the successful copolymerization reactions, and the thermal stabilities of the resulting copolymers were investigated by DMA and TGA. These results indicated that the $T_{\mathrm{g}}$ values of the prepared copolymers can be varied by changing the comonomer. Future studies should focus on the use of additional comonomers, such as acrylamides and acrylonitriles, which are known to be suitable for application in GTP systems, to gain a better understanding of the comonomer scope and to develop high-performance polymeric materials. 
Acknowledgements This research was financially supported by JSPS KAKENHI Grant Numbers 26410199 and 18K05210. This research is based on results obtained with the support of RIKEN-AIST Joint Research Fund Full Research.

Author contributions MI and YT designed and performed the experiments and analyzed the data. All the authors discussed the results and commented on the manuscript.

\section{Compliance with ethical standards}

Conflict of interest The authors declare no competing interests.

Publisher's note Springer Nature remains neutral with regard to jurisdictional claims in published maps and institutional affiliations.

Open Access This article is licensed under a Creative Commons Attribution 4.0 International License, which permits use, sharing, adaptation, distribution and reproduction in any medium or format, as long as you give appropriate credit to the original author(s) and the source, provide a link to the Creative Commons license, and indicate if changes were made. The images or other third party material in this article are included in the article's Creative Commons license, unless indicated otherwise in a credit line to the material. If material is not included in the article's Creative Commons license and your intended use is not permitted by statutory regulation or exceeds the permitted use, you will need to obtain permission directly from the copyright holder. To view a copy of this license, visit http://creativecommons. org/licenses/by/4.0/.

\section{References}

1. Webster OW, Hertler WR, Sogah DY, Farnham WB, RajanBabu TV. Group-transfer polymerization. 1. A new concept for addition polymerization with organosilicon initiators. J Am Chem Soc. 1983;105:5708-9.

2. Hertler WR, Sogah DY, Webster OW. Group-transfer polymerization. 3. Lewis acid catalysis. Macromolecules. 1984;17:1415-7.

3. Sogah DY, Hertler WR, Webster OW, Cohen GM. Group transfer polymerization. Polymerization of acrylic monomers. Macromolecules. 1987;20:1473-88.

4. Zhuang R, Müller AHE. Group transfer polymerization of n-butyl acrylate with lewis acid catalysts. 1. kinetic investigation using HgI2 as a catalyst in toluene. Macromolecules. 1995;28:8035-42.

5. Zhuang R, Müller AHE. Group transfer polymerization of n-butyl acrylate with lewis acid catalysts. 2 . Kinetic investigation using the $\mathrm{HgI}$ 2/Me3SiI catalyst system in toluene and methylene chloride. Macromolecules. 1995;28:8043-50.

6. Adams F, Pahl P, Rieger B. Metal-catalyzed group-transfer polymerization: a versatile tool for tailor-made functional $(\mathrm{Co})$ polymers. Chem Eur J. 2018;24:509-18.

7. Kakuchi R, Chiba K, Fuchise K, Sakai R, Satoh T, Kakuchi T. Strong Brønsted acid as a highly efficient promoter for group transfer polymerization of methyl methacrylate. Macromolecules. 2009;42:8747-50.

8. Fuchise K, Chen Y, Satoh T, Kakuchi T. Recent progress in organocatalytic group transfer polymerization. Polym Chem. 2013;4:4278-91.

9. Blumenstein J, Albert J, Schulz RP, Kohlpaintner C. Crotonaldehyde and crotonic acid. In: ULLMANN'S Encyclopedia of Industrial Chemistry. Weinheim: Wiley-VCH; 2015.

10. Garbe D. Cinnamic acid. In: ULLMANN'S encyclopedia of industrial chemistry. Weinheim: Wiley-VCH; 2015.
11. Sapiro RH, Linstead RP, \& Newitt DM Liquid-phase reactions at high pressures. Part II. The polymerisation of olefins. J. Chem. Soc. 1937:1784-90.

12. Marvel CS, McCain GH. Polymerization of esters of cinnamic acid. J Am Chem Soc. 1953;75:3272-3.

13. Matsumoto A, Horie A, Otsu T. Synthesis of substituted polymethylenes from alkyl cinnamates bearing bulky alkyl ester groups. Eur Polym J. 1992;28:213-7.

14. Holmes-Walker WA, Weale KE. Liquid-phase reactions at high pressure. Part IX. The polymerisation of some 1:2-disubstituted ethylenes. J. Chem. Soc. 1955:2295-301.

15. Hemmings RL, Weale KE. Rates of polymerization of diethyl fumarate and trans-ethyl cinnamate at high pressures. Polymer. 1986;27:1819-22.

16. Weale KE. Hindered initiation, primary-radical termination and effects of pressure on polymerization rates. Polymer. 1987;28: 2151-6.

17. Tsuruta T, Makimoto T, Tanabe K. Anionic polymerization of $\beta$ substituted acrylic esters. Makromol Chem. 1968;114:182-200.

18. Graham RK, Moore JE, Powell JA. Preparation and properties of polymers of secondary alkyl crotonates and related monomers. J Appl Polym Sci. 1967;11:1797-805.

19. Miller ML, Skogman J. Polymerization of tert-butyl crotonate. J Polym Sci Part A: Gen Pap. 1964;2:4551-8.

20. Makimoto T, Tanabe K, Tsuruta T. Anionic polymerization of methyl crotonate. Makromol Chem. 1966;99:279-81.

21. Tsuruta T, Makimoto T, Miyazako T. Reaction modes and polymerization of crotonic esters with lithium aluminum hydride. Makromol Chem. 1967;103:128-39.

22. McGraw M, Chen EY-X. Catalytic lewis pair polymerization of renewable methyl crotonate to high-molecular-weight polymers. ACS Catal. 2018;8:9877-87.

23. McGraw ML, Chen EY-X. Borane/silane frustrated lewis pairs for polymerization of $\beta$-substituted michael acceptors. Tetrahedron. 2019;75:1475-80.

24. Clarke RW, McGraw ML, Gowda RR, Chen EY-X. Lewis pair polymerization of renewable indenone to erythro-ditactic high-Tg polymers with an upcycling avenue. Macromolecules. 2020;53: 640-8.

25. Ute K, Tarao T, Hatada K. Group transfer polymerization of methyl crotonate. Polym J. 1997;29:957-8.

26. Ute K, Tarao T, Hongo S, Ohnuma H, Hatada K, Kitayama T. Preparation of disyndiotactic poly(methyl crotonate) by stereospecific group transfer polymerization. Polym J. 1999;31:177-83.

27. Ute K, Tarao T, Nakao S, Kitayama T. Preparation and properties of disyndiotactic poly(alkyl crotonate)s. Polymer. 2003;44: 7869-74.

28. Ute K, Tarao T, Kitayama T. Enhanced stereocontrol in disyndiotactic-specific group transfer polymerization of methyl crotonate - stereochemical evidence of group transfer. Polym J. 2005;37:578-83.

29. Takenaka Y, Abe H. Group-transfer polymerization of various crotonates using organic acid catalysts. Macromolecules. 2019;52: 4052-8.

30. Imada $M$, Takenaka $Y$, Hatanaka $H$, Tsuge $T$, Abe $H$. Unique acrylic resins with aromatic side chains by homopolymerization of cinnamic monomers. Commun Chem. 2019;2:109.

31. Atabaki F, Abdolmaleki A, Barati A. Free radical copolymerization of methyl methacrylate and N-2-methyl-4-nitrophenylmaleimide: improvement in the Tg of PMMA. Colloid Polym Sci. 2016;294:455-62.

32. Teng H, Yang L, Mikes F, Koike Y, Okamoto Y. Property modification of poly(methyl methacrylate) through copolymerization with fluorinated aryl methacrylate monomers. Polym Adv Technol. 2007;18:453-7. 
33. Hamada K, Morishita Y, Kurihara T, Ishiura K. Methacrylate-based polymers for industrial uses. In: Anionic polymerization 1011-31. Heidelberg: Springer; 2015.

34. McGraw ML, Clarke RW, Chen EY-X. Compounded sequence control in polymerization of one-pot mixtures of highly reactive acrylates by differentiating Lewis Pairs. J Am Chem Soc. 2020; 142:5969-73.

35. Brittain WJ, Dicker IB. Termination in group transfer polymerization. Macromolecules. 1989;22:1054-7.

36. Brittain WJ, Dicker IB. Termination processes in group transfer polymerization. Makromol Chem, Macromol Symp. 1993;67:373-86.

37. Imada M, Takenaka Y, Tsuge T, Abe H. Kinetic modeling study of the group-transfer polymerization of alkyl crotonates using a silicon Lewis acid catalyst. Polym Chem. 2020;11:5981-91.
38. Terao Y, Satoh K, Kamigaito M. Controlled radical copolymerization of cinnamic derivatives as renewable vinyl monomers with both acrylic and styrenic substituents: reactivity, regioselectivity, properties, and functions. Biomacromolecules. 2019;20:192-203.

39. Fujimori K, Schiller WS, Craven IE. Copolymerization of maleic anhydride with ethyl cinnamate and anethole in chloroform. Makromol Chem. 2019;192:959-66.

40. Bevington JC, Colley FR, Ebdon JR. Copolymers of methyl methacrylate with cinnamic acid. Polymer. 1973;14:409-10.

41. Wieting JM, Fisher TJ, Schafer AG, Visco MD, Gallucci JC, \& Mattson AE. Preparation and catalytic activity of BINOL-derived silanediols. Eur J Org Chem. 2015;2015:525-33.

42. Wypych G. Handbook of polymers. Toronto: ChemTec Publishing; 2012. 